\title{
PENJUALAN PRODUK IB HASANAH CARD MELALUI PROMOTION MIX PADA BNI SYARIAH CAB. KOTA PALANGKA RAYA
}

\author{
Jirhanuddin $^{1}$, Jelita, ${ }^{2}$ dan Hasanah $^{3}$
}

\begin{abstract}
Promotion and selling is an important function that the key to successful banking operations. Banks should be able to see the needs and tastes of the dynamic market with highly competitive conditions. Moreover, products and services in Islamic banking is still new and is not widely known to the public so it must have its own character in the marketing and sales strategies. And here the authors are interested in researching the product sales iB Hasanah Card through the promotion, because it is supported also by the narrative of one of the employees of BNI sharia city of Palangkaraya stating that there is significant influence on variables Promotion product mix on sales volume iB Hasanah this card, plus another in 2015, Bank Indonesia (BI) has issued rules restricting the credit card ownership by age and income.

The formulation of the problem in this research; (1) How does the product characteristics iB Hasanah card (2) How can the sale of products iB Hasanah Card. This field research using qualitative descriptive approach, which is the object of research is the sale of products through the iB Hasanah Card Promotion mix on BNI Syariah Cab. While the research subjects were 2 employees in positions related. Methods of data collection using observation, interviews, and documentation. While the validity of the data is also attested by the triangulation technique, and then the data were analyzed through the method of collection, reduction, display, and Conclusions.

With a wide range of references theory used to support the research, the results showed that, the sale of products iB Hasanah Card through the promotion mix that has the largest percentage is advertising, which have a percentage of both is personal selling, the third is a public relations (public relations) or publicity and the percentage The fourth is a sales promotion. Where the largest percentage occurred in 2015 which amounted to $4.18 \%$ and the lowest percentage occurred in 2012 which amounted to $1.45 \%$. Based on the results of the above data can be authors conclude also that in 2014 to 2015 only the advertising decreased from $65.97 \%$ to $60.38 \%$ it reinforces the reasons of the problems occurred that a change in Bank Indonesia Regulation No.14 / 2 / PBI / 2012 dated January 6, 2012 on Amendment to Bank Indonesia Regulation Number 11/11 / PBI / 2009 regarding Organization Card Payment Instrument.
\end{abstract}

\section{Keywoard: Promotion Mix, Product Sale}

\footnotetext{
${ }^{1}$ Direktur Pasca Sarjana IAIN Palangka Raya.

${ }^{2}$ Ketua Jurusan Ekonomi Islam IAIN Palangka Raya.

${ }^{3}$ Mahasiswa IAIN Palangka Raya,
} 


\section{A. PENDAHULUAN}

Seiring dengan perkembangan lembaga keuangan perbankan syari'ah di Indonesia, maka salah satu ekspansi pasar perbankan Syariah saat ini ialah dengan terbitnya APMK (Alat Pembayaran Menggunakan Kartu) seperti kartu kredit yang telah menjadi bagian kehidupan manusia, terutama bagi masyarakat yang tinggal di kota.

Perkembangan bisnis kartu kredit di Indonesia semakin pesat dalam beberapa tahun terakhir. Jumlah kartu yang beredar saat ini telah mencapai lebih dari 13 juta kartu yang diterbitkan oleh 22 bank dan lembaga pembiayaan. Bertepatan dengan Festival Ekonomi Syariah (FES) pada bulan Februari 2009 yang diselenggarakan oleh Bank Indonesia, BNI Syariah telah melaunching salah satu jenis pembiayaan yang berbasis kartu kredit yaitu Hasanah Card dengan menggandeng provider MasterCard Internasional.Pada satu sisi penetrasi yang luar biasa ini menguntungkan bagi banyak perusahaan perbankan penerbit kartu kredit. Tetapi di sisi lain mengkhawatirkan karena akhirnya banyak ditemui pengguna kartu kredit yang tidak bertanggung jawab.Oleh karena itu, memasuki tahun 2015, Bank Indonesia (BI) menerbitkan aturan yang membatasi kepemilikan kartu kredit berdasarkan usia dan pendapatan. Kedepannya anggota masyarakat yang berpenghasilan Rp 3 juta- Rp 10 juta per bulan tidak akan diperbolehkan memiliki lebih dari dua kartu kredit dari penerbit yang berbeda. ${ }^{4}$

Marketing dan selling merupakan fungsi penting yang menjadi kunci keberhasilan operasional perbankan. Bank harus mampu melihat kebutuhan dan selera pasar yang dinamis dengan kondisi yang sangat kompetitif. Proses penjulan dan pemasaran di dunia perbankan relatif berbeda dengan produk dan jasa industri lain. Apalagi produk dan jasa dalam perbankan syariah masih baru serta masih belum banyak dikenal masyarakat sehingga harus memiliki karakter tersendiri dalam strategi pemasaran dan penjualannya.

Berkaitan dengan permasalahan penerapan variabel marketing mix yang dikenal dengan istilah $4 \mathrm{p}$ yakni product, price, place dan promotion terhadap volume penjualan produk.Maka menurut penulis, terdapat bagian penting seperti pada bagian promotion yang dapat meningkatkan pemasaran produk perbankan itu sendiri. Dan disini penulis tertarik meneliti terkait produk iB Hasanah Card Melalui promotion mix, di BNI Syariah cabang kota Palangka Raya dalam menerapkan program-program promosinya. Hal ini didukung pula dengan penuturan dari salah satu karyawan BNI Syari' ah di kota Palangka Raya menyatakan bahwa terdapat pengaruh pada variabel-variabel Promotion mix terhadap volume penjualan produk iB Hasanah card ini, Apalagi jika dilihat dari masa berdirinya dikota Palangka Raya yang masih tergolong baru. Ditambah lagi di tahun 2015 ini Bank Indonesia (BI) menerbitkan aturan yang membatasi kepemilikan kartu kredit berdasarkan usia dan pendapatan ${ }^{5}$ Permasalahan ini menjadi menarik, sejatinya untuk meningkatkan volume penjualan produk iB Hasanah card dengan mengendalikan pola menangkap peluang pasar di kota Palangka Raya. Oleh karena itu, penelitian yang akan dilakukan ini diberi judul "PENJUALAN

${ }^{4}$ Peraturan Bank Indonesia No.14/2/PBI/2012 tanggal 6 Januari 2012 tentang Perubahan Atas Peraturan Bank Indonesia Nomor 11/11/PBI/2009 tentang Penyelenggaraan Kegiatan Alat Pembayaran Dengan Menggunakan Kartu.

${ }^{5}$ Wawancara dengan salah satu karyawan di kantor BNI Syariah Cabang Kota Palangka Raya, pada tanggal 22 september 2015, 14.00 WIB. 


\section{PRODUK IB HASANAH CARD MELALUI PROMOTION MIX PADA BNI SYARIAH CAB. KOTA PALANGKA RAYA".}

\section{B. LANDASAN TEORI}

\section{Promotion}

Promosi merupakan sarana yang paling ampuh untuk menarik dan mempertahankan nasabahnya. Salah satu tujuan promosi bank adalah menginformasikan segala jenis produk yang ditawarkan dan berusaha menarik calon nasabah yang baru. ${ }^{6}$ Selanjutnya perusahaan dalam hal ini adalah bank harus mampu mencari cara agar bisa mencapai efektifitas dari satu atau lebih alat promosi. Dalam menentukan alat promosi, manajer pemasaran bank harus mengenal ciri masing-masing alat promosi yang akan digunakan tersebut. Variabel promosi atau yang lazim disebut bauran pemasaran (promotion mix) antara lain personal selling, advertising, sales promotiondanpublic relation.

a. Personal selling, yaitu interaksi langsung antara satu atau lebih calon pembeli dengan tujuan melakukan penjualan. ${ }^{7}$ Dalam dunia perbankan penjualan pribadi secara umum dilakukan oleh seluruh pegawai bank, mulai dari cleaning service,satpam sampai pejabat bank. Secara khusus personal selling dilakukan oleh petugas costumer service atau service assistensi. ${ }^{8}$

b. Advertising, yaitu semua bentuk presentasi nonpersonal dan promosi ide, barang, atau jasa oleh sponsor yang ditunjuk dengan mendapat bayaran. Iklan adalah segala bentuk penyajian informasi dan promosi secara tidak langsung yang dilakukan oleh sponsor untuk menawarkan ide, barang, atau jasa. Iklan dibuat menarik perhatian dan mudah diingat dengan tujuan untuk mempengaruhi orang agar membeli barang atau jasa tertentu. ${ }^{9}$

c. Sales promotion, yaitu insentif jangka pendek untuk mendorong keinginan mencoba atau pembelian produk dan jasa. ${ }^{10}$ Tujuan promosi penjualan (sales promotion) adalah untuk meningkatkan penjualan atau untuk meningkatkan jumlah nasabah. ${ }^{11}$

d. Public relations and publicity, yaitu berbagai program yang dirancang untuk mempromosikan dan/atau melindungi citra perusahaan atau produk individual yang dihasilkan. ${ }^{12}$ Promosi yang terakhir adalah publisitas, di mana kegiatan seperti pameran, pembukaan stan promosi dipusat pembelanjaan, sponsorship kegiatan, program corporate social responcibility (CSR), mendukung atau berperan serta dalam kegiatan amal seperti penggalangan dana untuk para korban bencana alam serta kegiatan lainnya. $^{13}$

\footnotetext{
${ }^{6}$ Kasmir, Manajemen Perbankan..., h. 213.

${ }^{7}$ Https://daraadilasandy.wordpress.com/2011/05/28/bauran-pemasaran-marketing-mix/html . (Di akses pada 20 Mei 2015).

${ }^{8}$ Kasmir, Manajemen Perbankan..., h. 215.

${ }^{9}$ Titik Nurbiyati, Mahmud Machfoedz, Manajemen Pemasaran..., h. 209.

${ }^{10} \mathrm{Https}$ ://daraadilasandy.wordpress.com/2011/05/28/bauran-pemasaran-marketing-mix/html . (Di akses pada 20 Mei 2015).

${ }^{11}$ Kasmir, Manajemen Perbankan..., h. 214.

${ }^{12} \mathrm{Https}$ ://daraadilasandy.wordpress.com/2011/05/28/bauran-pemasaran-marketing-mix/html . (Di akses pada 20 Mei 2015).

${ }^{13}$ Al Arif, NurRianto, Dasar-Dasar Pemasaran Bank Syari'ah,... h. 185-186.
} 


\section{Volume Penjualan}

Pakar pemasaran Philip Kotler mendifinisikan bahwa marketing merupakan fungsi organisasi yang berproses mencipta, mengomunikasikan, dan memberikan nilai (value) bagi costumer, serta mengelola hubungan yang menguntungkan bagi perusahaan dan bagi segenap pemangku kepentingan (stokeholders). Pemasaran berawal dari informasi pasar, produksi, edukasi pasar, penjualan, proses membina hubungan baik dengan costumer, serta upaya meningkatkan loyalitas pelanggan. Sedangkan selling merupakan proses penjualan produk dan jasa dengan tujuan pencapaian penjualan sebagai bagian dari marketing. ${ }^{14}$

\section{Karakteristik Produk iB Hasanah Card}

iB Hasanah Card merupakan kartu pembiayaan yang berfungsi sebagai kartu kredit berdasarkan prinsip Syariah, yaitu dengan sistem perhitungan biaya yang bersifat tetap, adil, transparan dan kompetetif tanpa bunga. iB hasanah card adalah kartu berbasis Syariah yang berfungsi seperti kartu pembiayaan sehingga diterima di seluruh tempat bertanda MasterCard dan semua ATM yang bertanda CIRRUS di seluruh dunia.

Dasar yang dipakai dalam penerbitan Hasanah Card adalah fatwa Dewan Syariah Nasional (DSN) No. 54/DSN/MUI/X/2006 mengenai Syariah Card dan surat persetujuan dari Bank Indonesia No. 10/337/DPbs tangal 11-03-2008. iB hasanah card adalah salah satu kartu kredit yang menggunakan akad Syariah, yang diterbitkan oleh BNI Syariah, berikut ketentuan Fatwa Berdasarkan Fatwa DSN No. 54/DSN-MUI/X/2006 akad Hasanah Card terdiri dari 3 jenis, yaitu: Akad kafalah, Qard, dan Ijarah.

iB hasanah card tidak digunakan untuk transaksi yang tidak sesuai dengan Syariah dan juga tidak mendorong pengeluaran yang berlebihan (israf) Pemegang iB hasanah card harus memiliki kemampuan financial untuk melunasi pada waktunya. iB hasanah card terdiri dari 3 jenis kartu : classic, gold dan platinum. iB Hasanah Card dapat diterima sebagai alat pembayaran di lebih 29 juta tempat usaha yang memasang logo MasterCard di seluruh dunia. iB Hasanah Card juga memiliki fasilitas pengambilan uang tunai melalui ATM BNI maupun ATM bank lain yang memiliki jaringan MasterCard di seluruh dunia. Hasanah Card sebagai salah satu produk layanan dari BNI Syariah memiliki slogan "Karena halal juga menguntungkan" slogan ini mencerminkan bahwa setiap transaksi yang didukung oleh Hasanah Card dengan merchant kepada nasabah adalah transaksi yang bersifat halal, tidak merugikan, dan tentunya membantu nasabah kepada transaksi yang menguntungkan. ${ }^{15}$

\section{Penjualan produk iB hasanah card melalui promotion mix pada bni syariah cab. Kota palangka raya}

Volume Penjualan menurut Asri (1991:52) adalah jumlah unit penjualan nyata perusahaan dalam

satu periode tertentu. Jadi volume penjualan dapat dikatakan sebagai hasil kegiatan penjualan yang diukur dengan satuan. Menurut Kotler yang dikutip Swastha dan Irawan (2003:404), menyimpulkanbahwa ada beberapa indikator dari volume penjualan adalah

\footnotetext{
${ }^{14}$ Fatkur Rohman, Memahami Bisnis Bank Syariah, Jakarta:Gramedia Pustaka Utama, 2014, h. 314-
} 315.

${ }^{15}$ Https://bnisyariah.co.id.html . (Di akses pada 11 April 2016). 
sebagai berikut: 1 . Mencapai volume penjualan tertentu; 2. Mendapatkan laba tertentu; 3 . Menunjang pertumbuhan perusahaan. ${ }^{16}$

Berdasarkan hasil observasi, wawancara serta data-data pendukung lainnya, penulis akan memaparkan beberapa aktivitas promotion mix yang telah dilaksanakan oleh pihak BNI Syariah Cab. Kota Palangka Raya, diantaranya:

\section{a) Penjualan secara personal (Personal Selling)}

Dalam menawarkan produk Hasanah Card Ada beberapa teknik yang biasa BNI Syariah yakni membangun tatap muka langsung dengan nasabahnya. Sifat penjualan yang dilakukan BNI Syariah terhadap produk Hasanah Card melalui hubungan langsung dan interaktif antara dua orang atau lebih. Dengan penjualan secara personal, adapun tujuan utama yang ingin dicapai oleh BNI Syariah yaitu menghijrahkan pengguna kartu konvensional ke kartu kredit Hasanah Card.

b) Advertising (Advertising)

BNI Syariah dalam mempromosikan produk Hasanah Card salah satunya adalah menggunakan advertising. Advertising menjadi suatu sarana untuk memperkenalkan produk Hasanah Card ini, terlebih Hasanah Card ini adalah produk baru. Dan BNI Syariah memanfaatkan beberapa koran sebagai tempat untuk promosi produknya dalam bentuk pasang iklan.

\section{c) Promosi Penjualan(Sales Promotion)}

Persuasi (ajakan) langsung melalui penggunaan berbagai insentif saat ini dilakukan oleh BNI Syariah agar merangsang konsumen melakukan pembelian produk dengan segera, dan juga meningkatkan jumlah barang yang dibeli pelanggan. Promosi penjualan pun dilakukan oleh perusahaan dengan tujuan seperti menarik pelanggan baru, mempengaruhi pelanggan lama BNI Syariah untuk mencoba produk Hasanah Card, menyerang aktivitas promosi pesaing, dan meningkatkan pembelian tanpa rencana sebelumnya (Impulse buying). Promosi penjualan oleh BNI Syariah berdasarkan periode promo, jadi kadang berganti-ganti apabila periode promonya telah selesai. ${ }^{17}$

\section{d) Publisitas dan Hubungan Masyarakat}

Secara teknis Publisitas dilakukan oleh EO tersebut baik melalui media sosial (Facebook, twitter) secara menyebar, internet (dalam bentuk pemberitaan), dan pemasangan logo di web kepanitiaan. BNI Syariah melakukan kegiatan Hubungan Masyarakat untuk mempengaruhi persepsi, keyakinan dan sikap konsumen terhadap produk Hasanah Card.

Adapun bagian penting dalam perencanaan promosi BNI Syariah adalah dengan melakukan penetapan anggaran promosi. Anggaran promosi ini merupakan langkah lanjutan setelah perusahaan menetapkan tujuan dari kegiatan promosi. Penetapan besarnya anggaran promosi dilakukan oleh divisi Hasanah Card BNI Syariah dengan mempertimbangkan kebutuhan masyarakat yang besarannya menyesuaikan dengan tingkat kemampuan perusahaan (Arbitrary).

\footnotetext{
${ }^{16}$ Erwin Budiman, S. Pangemanan, S. Tangkuman, Analisis Perlakuan Akuntansi..., Jurnal EMBA Vol.2 No.1 Maret 2014, h. 421-430.

${ }^{17}$ Berdasarkan hasil observasi penelitian pada tanggal 15 April 2016 di Kantor BNI Syari'ah cabang Palangka Raya.
} 
Tabel 3. Persentase Promotion Mix Tahun 2012-2015

\begin{tabular}{ccccc}
\hline Tahun & $\begin{array}{c}\text { Personal } \\
\text { Selling }\end{array}$ & Advertising & Sales Promotion & Publisitas \\
\hline $\mathbf{2 0 1 2}$ & 12.572 & 4.177 & 254 & 553 \\
& $71.61 \%$ & $23.79 \%$ & $1.45 \%$ & $3.15 \%$ \\
$\mathbf{2 0 1 3}$ & 7.608 & 12.097 & 460 & 379 \\
& $37.03 \%$ & $58.88 \%$ & $2.24 \%$ & $1.84 \%$ \\
$\mathbf{2 0 1 4}$ & 4.797 & 11.151 & 507 & 448 \\
& $28.38 \%$ & $65.97 \%$ & $3.00 \%$ & $2.65 \%$ \\
\hline
\end{tabular}

Sumber: Diolah penulis berdasarkan dokumen BNI Syariah cabang Palangka Raya tahun 2016.

Dari hasil analisis diatas dapat dilihat bahwa pada tahun 2014 ke 2015 hanya advertising yang mengalami penurunan yakni dari $65,97 \%$ ke $60,38 \%$ hal ini memperkuat alasan dari permasalahan yang terjadi yakni berdasarkan penuturan karyawan BNI Syariah pada observasi awal ternyata memang ada pengaruh pada salah satu dari promotion mix yang ternyata ialah advertising. Sedangkan mengenai pemegang kartu yang bermasalah seperti pengguna kartu kredit yang tidak bertanggung jawab, maka aturan $\mathrm{BI}^{18}$ pun menurut $\mathrm{AS}$ seperti yang telah diuraikan diatas bahwa telah diberlakukan.Hal inipun selaras dengan peraturan yang dikeluarkan BI pada tahun 2015 mengenai penggunaan kartu kredit sesuai usia dan pendapatan

\section{PENUTUP}

\section{Kesimpulan}

Berdasarkan penelitian yang telah dilakukan serta hasil penelitian yang diperoleh yang telah dipaparkan pada bab-bab sebelumnya mengenai penjualan Produk iB Hasanah Card di BNI Syariah cab. Palangka Raya, maka dapat ditarik kesimpulan menunjukkan bahwa penjualan produk iB Hasanah Card melalui promotion berdasarkan hasil analisis penulis menyimpulkan bahwa personal selling, advertising, sales promotion dan publisitas telah ditelaksanakan di BNI Syariah namun dalam hal penerapan di aktivitas periklanan yang lainnya terdapat beberapa yang belum digunakan seperti pada media elektronik oleh BNI Syariah Cab. Kota Palangka Raya diantaranya:, a). TVatau Ad Lips Ad Lips yakni merupakan iklan yang berupa bentuk suara yang biasanya dikhususkan kepada para target

\footnotetext{
${ }^{18}$ Peraturan Bank Indonesia No.14/2/PBI/2012 tanggal 6 Januari 2012 tentang Perubahan Atas Peraturan Bank Indonesia Nomor 11/11/PBI/2009 tentang Penyelenggaraan Kegiatan Alat Pembayaran Dengan Menggunakan Kartu.
} 
konsumen. Hal ini pun selaras dengan data yang didapat penulis bahwa pada tahun $2014 \mathrm{ke}$ 2015 hanya advertising yang mengalami penurunan yakni dari $65,97 \%$ ke 60,38\% hal ini memperkuat alasan dari permasalahan yang terjadi yakni berdasarkan penuturan karyawan BNI Syariah pada observasi awal ternyata memang ada pengaruh pada salah satu dari promotion mix yang ternyata ialah advertising.

\section{Saran}

Setelah melakukan penelitian penjualan produk iB Hasanah Card melalui promotion mixdi BNI Syariah, maka peneliti memberikan saran kepada BNI Syariah dan penelitilain yang akan menjadikan penelitian ini sebagai rujukan.

a. Bagi Bank BNI Syariah

Berdasarkan penelitian yang telah peneliti lakukan, maka penelitimendapatkan hasil bahwa produk keunggulan Bank BNI Syariah yakniproduk iB Hasanah Card terus mengalami perkembangan padasetiap tahunnya. Dengan hasil tersebut, hendaknya pihak Bank BNISyariah selalu memberikan inovasi-inovasi baru terhadap setiap produkproduknya agar masyarakat mempunyai ketertarikan untuk menggunakan kartu tersebut dan nasabah tetap mempertahankannya.

\section{b. Bagi Peneliti Lain}

Bagi peneliti lain yang akan melakukan penelitian tentang produk iB Hasanah Card hendaknya lebih mengembangkan penelitiannya dalampendapat nasabah dan kepuasan nasabah, karena penelitian ini hanyasebatas karakteristik dan penjualan produk iB Hasanah Card setiap akhirtahunnya.Berdasarkan kesimpulan dan keterbatasan di atas,maka penulis menyarankan pula agar penelitian selanjutnya diharapkan agar dapat menggunakan faktor - faktor lain yang berdampakpada besar kecilnya $f$ in dalam suatu produk ataupun usaha-usaha lainnya.

\section{DAFTAR PUSTAKA}

\section{A. Library Reseach}

Abdullah, Thamrin dan Francis Tantri, Manajemen Pemasaran, Jakarta: Raja Grafindo Persada, 2012.

Al Arif, NurRianto, Dasar-Dasar Pemasaran Bank Syari'ah, Bandung: Alfabeta, 2010.

Arikunto, Suharsimi, Prosedur Penelitian Suatu Pendekatan Praktik, Jakarta: PT. Rineka Cipta, 1993.

Assauri, Sofjan, Strategi Marketing, Jakarta: Raja Grafindo Persada, 2012.

Budiman, Erwin, S. Pangemanan, S. Tangkuman, Analisis Perlakuan Akuntansi... 424 Jurnal EMBA Vol.2 No.1 Maret 2014.

Bungin, Burhan, Penelitian Kualitatif: Komunikasi, Ekonomi, Kebijakan Publik, dan Ilmu Sosial Lainnya, cet. IV, Jakarta: Kencana, 2010.

Bungin, Burhan, Analisis Data Penelitian Kualitatif, Jakarta: PT. Raja Grafindo Persada, 2003.

Corbin Juliet dan Anslem Strauss, Dasar-DasarPenelitianKualitatif, alihbahasa $\mathrm{M}$. Shodiqdan Imam Muttaqien, Yogyakarta: PustakaPelajar, 2009. 
Dawson, Catherine, Metode Penelitian Praktis: Sebuah Panduan, (Terj.) M. Widiono, Yogyakarta: Pustaka Poelajar, 2010, cet. I.

Departemen Agama Republik Indonesia, Al-Qur'an Dan Terjemahnya Mushaf Al-Burhan Edisi Wanita Tajwid, Bandung: Media Fitrah Rebbani.

Fathoni, Abdurrahmat Metodologi Penelitian \& Teknik Penyusunan Skripsi, Jakarta: PT. Rineka Cipta, 2006.

Gunara,Thorik, Utus Hardiono, Marketing Muhammad: Strategi Andal dan Jitu Praktik Bisnis Nabi Muhahammad Saw, Bandung: Salamadani Pustaka Semesta, 2007.

Hasan, Ali, Marketing Bank Syariah: Cara Jitu Meningkatkan Pertumbuhan Pasar Bank Syariah, Bogor: Ghalia Indonesia, 2010.

Hurriyati, Ratih, Bauran Pemasaran dan Loyalitas Konsumen, Bandung: IKAPI, 2005.

Kasmir, Pemasaran Bank, Jakarta: Kencana, 2010.

Kasmir, Manajemen Perbankan, Jakarta: Raja Grafindo Persada, 2010.

Kotler, Philip, Kevin Lane Keller, Manajemen Pemasaran, Indonesia: Macanan Jaya Cemerlang, 2008.

Mardalis, Metode Penelitian SuatuPendekatan Proposal, Jakarta: BumiAksara, 2004.

Moleong, Lexy J., Metodologi Penelitian Kualitatif, Bandung: Remaja Rosdakarya, 2000.

Morissan, Periklanan: Komunikasi Pemasaran Terpadu, Jakarta: Kencana Frenada Media Group, 2010.

Nasution, Mustafa Edwin, dkk, Pengenalan Eksekutif Ekonomi Islam, Jakarta: Kencana, 2007.

Nurbiyati, Titik, Mahmud Mahchfoedz, Manajemen Pemasaran Kontemporer, Yogyakarta: Kayon, 2005.

Perreault, McCarthy, Intisari Pemasaran: Sebuah Ancangan Manajerial Global, Jakarta: Binarupa Aksara, 1995.

Rohman, Fatkur, Memahami Bisnis Bank Syariah, Jakarta:Gramedia Pustaka Utama, 2014.

Sarwono, Jonathan, Metode Penelitian Kuantitatif dan Kualitatif, Yogyakarta: Graha Ilmu, 2006.

Sugiyono, Memahami Penelitian Kualitatif, Bandung: ALFABETA, 2010, cet. VI

Sugiyono, MemahamiPenelitianKualitatif, Bandung: CV. Alfabeta, 2009.

Sholihin, Ahmad Ifham, Pedoman Umum Lembaga Keuangan Syari'ah, Jakarta: Gramedia Pustaka Utama, 2010.

Sopiah dan Etta Mamang Sangadji, Metodologi Penelitian, Yogyakarta: Andi Yogyakarta, 2010.

Subagyo, Joko, Metode Penelitian, Jakarta: PT. Rineka Cipta, 2004.

Sutanto, Herry, Khaerul Umam, Manajemen Pemasaran Bank Syariah, Bandung: Pustaka Setia, 2013.

Swastha, Basu, Azaz-azaz marketing, Yogyakarta: Liberty, 2002.

Syar'i, H. Ahmad, dkk, Pedoman Penulisan Skripsi, Palangka Raya: STAIN Palangka Raya Press, 2007.

Sunarto dan Riduan, Pengantar Statistika untuk Penelitian Pendidikan, Sosial, Ekonomi Komunikasi, dan Bisnis, Bandung: Alfabeta, 2007

Tan, Inggrid, Bisnis \& Investasi Sistem Syariah, Yogyakarta: Universitas Atma Jaya, 2009.

Tika, Moh Pabundu, Metodologi Riset Bisnis, Jakarta: Bumi Aksara, 2006. 
Tim Penyusun, dkk, Pedoman Penulisan Skripsi Sekolah Tinggi Agama Islam Negeri (STAIN) Palangka Raya Tahun 2007, Palangka Raya: STAIN Palangka Raya Press, 2007.

Tim Penyusun, dkk, Pedoman Penulisan Skripsi Sekolah Tinggi Agama Islam Negeri (STAIN) Palangka Raya Tahun 2013, Palangka Raya: STAIN Palangka Raya Press, 2013.

Tjiptono, Fandi, Pemasaran Jasa: Prinsip, Penerapan dan Penelitian, Yogyakarta: CV. Andi Offset, 2014.

Triton dan M. Hariwijaya, Pedoman Penelitian Ilmiah Skripsi dan Tesis, t.tp: Platinum, 2013.

Wijayanti, Titik, Marketing Plan dalam Bisnis, Jakarta: Gramedia, 2012.

\section{B. Internet Reseach}

Http://Lathifahbahrun.Blogspot.Com/2012/01/Bank-Syariah.Html (Di akses pada 29 Februari 2015).

Http://www.bnisyariah.co.id/en/persaingan-kartu-kredit-ketat-bni-syariah-bidik-segmenpendidikan-dan-komunitas (Di akses pada 20 Mei 2015).

Http://www.lebahmaster.com/tips-dan-trik/tips-marketing/pengertian-marketing-mix akses pada 5 April 2015).

Https://daraadilasandy.wordpress.com/2011/05/28/bauran-pemasaran-marketing-mix/html . (Di akses pada 20 Mei 2015).

Https://taniosutrisno.wordpress.com/2014/09/25/perilaku-konsumen-teori-ciri-ciri-danmanfaat-perilaku-konsumen/ (Di akses pada 20 Mei 2015).

Https://bnisyariah.co.id.html .(Di akses pada 11 April 2016).

Sejarah BNI Syariah, Http://www.bnisyariah.co.id/sejarah-bni-syariah, diakses pada tanggal (22 September 2015). 